九州大学学術情報リポジトリ

Kyushu University Institutional Repository

\title{
Color Pattern and Morphological Features of Dwarf Loach, Kichulchoia brevifasciata (Pisces: Cobitidae) from Korea
}

Kim, Eun-Jin

Institute for Biodiversity, Chonbuk National University

Mochioka, Nor i taka

Animal and Marine Bioresource Science, Bioresource Sciences, Faculty of Agriculture, Kyushu University

https://doi.org/10.5109/22055

出版情報：九州大学大学院農学研究院紀要. 57 (1)，pp.93-96，2012-02. Faculty of Agriculture， Kyushu University

バージョン:

権利関係: 


\title{
Color Pattern and Morphological Features of Dwarf Loach, Kichulchoia brevifasciata (Pisces: Cobitidae) from Korea
}

\section{Eun-Jin KIM* and Noritaka MOCHIOKA}

Laboratory of Fisheries Biology, Faculty of Agriculture, Kyushu University, Fukuoka, 812-8581, Japan

(Received October 31, 2011 and accepted November 9, 2011)

\begin{abstract}
Color patterns (including breeding colors), growth features and sexual dimorphism of the dwarf loach Kichulchoia brevifasciata were studied at a stream in Geumsan-myeon, Goheung-gun, Jeollanam-do, Korea. An oblique stripe from the snout tip to the eye disappeared with fish growth, concurrent with an increasing number of oval dots on the head. The opercular rim became golden-greenish during the spawning season. No significant morphological features were apparent between sexes, excepting females attained a larger body size.
\end{abstract}

Key words: color pattern, morphology, spawning season

\section{INTRODUCTION}

The freshwater fish, Family Cobitidae, distributed widely in Europe, Asia and Morocco, currently includes 177 species in 26 genera (Nelson, 2006; Kim, 2009). Cobitid fishes of Korea were classified as 16 species in 5 genera (Kim, 2009) on the structure of the lamina circularis at the base of pectoral fin in males (Vladykov, 1935), color patterns on the lateral body side and scale structure, according to external identification of the Cobitidae fishes (Mizuno, 1970; Kim, 2009).

Among Cobitidae fishes, genus Kichulchoia show remarkable morphological characters as caudal peduncle shorter than head, no Gambetta's zone on body sides (Gambetta, 1934), no lamina circularis, and 4 unbranched anal fin rays and 6 branched dorsal fin rays, respectively (Kim and Lee, 1995; Kim et al., 1997; Kim et al., 1999; Kim, 2009).

The dwarf loach, Kichulchoia brevifasciata (Kim and Lee, 1995), initially described as genus Niwaella (N. brevifasciata), was considered distinct from species in closely-related genera in lacking a dark oblique line from the snout to the eye and lamina circularis (Kim and Lee, 1995). Although the species was later placed in the new genus Choia, on the basis of 4 branched rays in the anal fin, by Kim et al. (1997), the latter name was preoccupied and subsequently replaced as Kichulchoia finally by Kim et al. (1999).

Subsequent investigations on $K$. brevifasciata have discussed its phylogenic relationships, following a molecular study (Kim et al., 2000; Šlechtová et al., 2008), distribution (Chae and Yoon, 2007) and chromosome numbers (Kim and Kim, 2008). However, there have been no detailed morphological or ecological studies following the initial description of the species.

By reason of $K$. brevifasciata is restricted to the extreme southwestern region of Korea and is under threat of extinction (Kim and Kim, 2008; Kim, 2009), the

* Corresponding Author: Eun-Jin KIM (E-mail: jaurlim@agr. kyushu-u.ac.jp) present study aimed to accumulate basic information pertinent to phylogenetic and ecological considerations, including lateral line and size-related color pattern variations, spawning colors, and morphological differences between females and males.

\section{MATERIALS AND METHODS}

A total of 50 individuals were captured for recording general color pattern variations, growth characteristics and sexual dimorphisms, using a hand net (mesh size $1 \mathrm{~mm}$ ) in a stream in Geumsan-myeon, Goheung-gun, Jeollanam-do, Korea in August to October, 2006. The specimens were subsequently fixed in $10 \%$ formaldehyde and deposited in the Ichthyology Laboratory, Faculty of Biological Science, Chonbuk National University, Jeonju, Korea (CNUC). Fifty individuals were captured similarly between April and August 2006 , so as to cover the spawning season (May to July) (Kim et al., unpublished data), their spawning colors recorded in the field and the fish released in the same area.

Color pattern variations were investigated following Gambetta (1934), Saitoh and Aizawa (1987) and Nalbant (1963). Following confirmation of sex by gonad dissection, morphological measurements were recorded and expressed as percentages of standard length (SL) or head length (HL) for adult males and females, using 1/20 $\mathrm{mm}$ dial calipers. Dorsal and ventral fin origins and pectoral fin ray shape were determined using soft X-rays (Hitex HA-80, Japan). Data for the sexual dimorphisms were compared using the two tailed Student's t-test (highly significant defined as $P<0.001$; significant as $P<0.05)$.

\section{RESULTS}

\section{Color pattern of dorsum}

Dorsal color patterns were generally dark brown, being classified into major types A, B and C (Fig. 1). Type A - mid-dorsally 13 to 17 rectangular blotches distinct from dense reticulate pattern of spots on dorso-lat- 
A

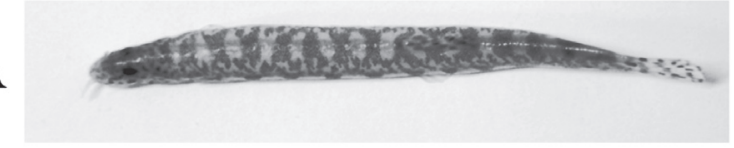

B

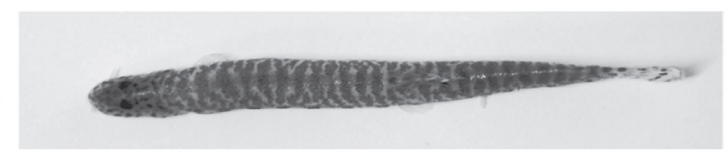

$\mathrm{C}$

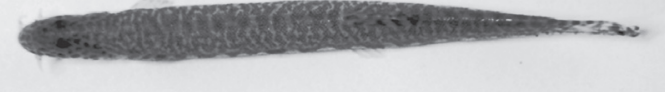

Fig. 1. Three types of dorsal color patterns in Kichulchoia brevifasciata.

A: Rectangular blotches with similar width interspaces; B: Many thin rectangular bands closely associated with upper body speckling; C: Bands poorly formed, having a vermiculate appearance.

eral region and separated by similar width interspaces (n = 15) (Fig. 1-A). Type B - mid-dorsally 22 to 25 dense thin rectangular bands united with speckled pattern on dorso-lateral region and separated by narrower width interspaces $(n=10)$ (Fig. 1-B). Type $\mathrm{C}$ - similar to Type $\mathrm{B}$, but with bands poorly formed and having a vermiculate appearance ( $\mathrm{n}=5$ ) (Fig. $1-\mathrm{C})$.

\section{Color pattern on lower lateral body surface}

Base color of body is light pale yellow and color of speckles on the lateral side is deep dark brown than upper part of body speckles. Generally 12 to 22 elongated spots, showing significant individual variation in shape, including oval, semicircular or bow-like, triangular, square and rectangular (Fig. 2-A, C, D) although more often an extended triangular bar (Fig. 2-B). Sometimes two or three spots coalesced into one (Fig. 2-C).

A

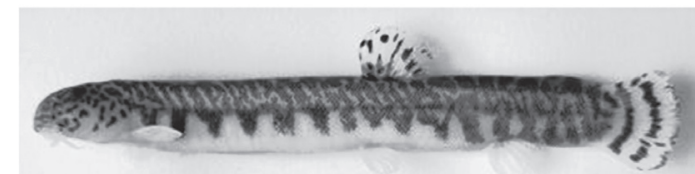

B

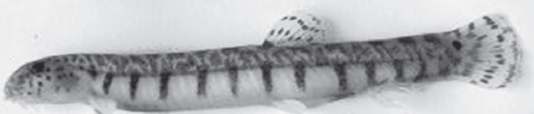

C

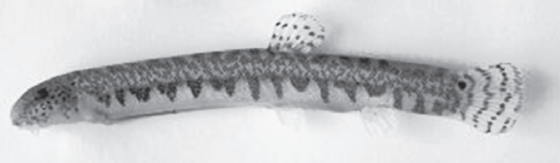

$\mathrm{D}$

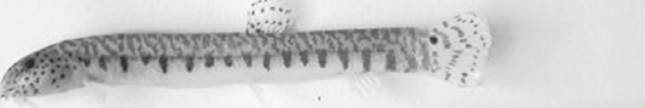

Fig. 2. Lower lateral color pattern variations in Kichulchoia brevifasciata.

A: Triangular, square and rectangular spots, $66.31 \mathrm{~mm}$ in TL; B: Vertically extended triangular spots, $53.25 \mathrm{~mm}$ in TL; C: Two or three coalesced spots, $52.36 \mathrm{~mm}$ in TL; D: Oval, semicircular or bow-like spots, $50.62 \mathrm{~mm}$ in TL.

\section{Color pattern transition on the head}

A dark brown line running obliquely from the barbel through the eyes to the occiput (Fig. 3) in juveniles (10 to $30 \mathrm{~mm} \mathrm{TL}$ ) (Fig. 3-A, B and C) becomes progressively less distinct with growth in adults ( 30 to $50 \mathrm{~mm}$ TL) (Fig. $3-\mathrm{D}, \mathrm{E}$ and $\mathrm{F}$ ), being almost completely lost in adults greater than $50 \mathrm{~mm}$ TL (Table 1). Concurrently, the number of oval dots on the head gradually increased from 6 to 33 (Table 1) (Fig. 3).

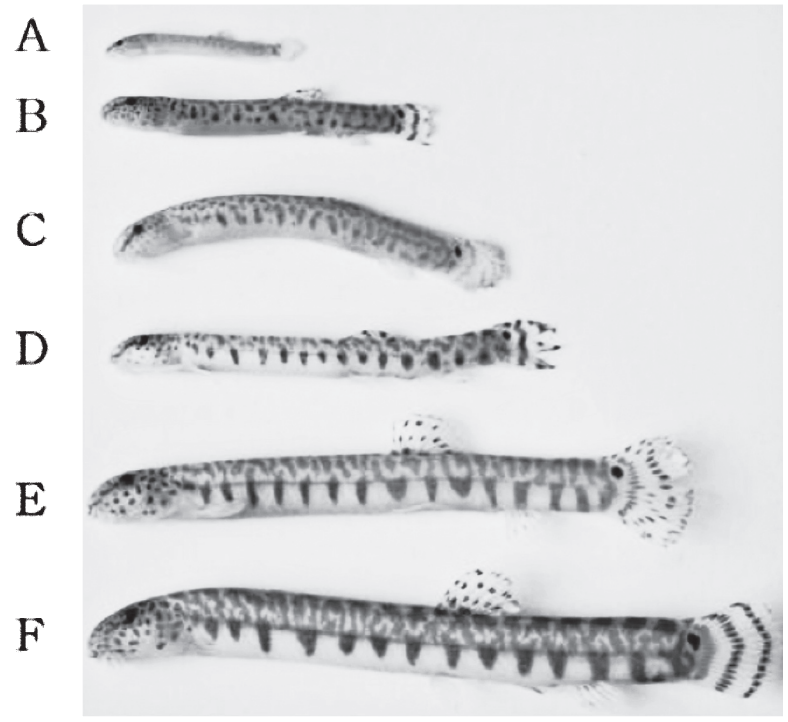

Fig. 3. Color pattern variations on the head of Kichulchoia brevifasciata.

A: Juvenile, $15.64 \mathrm{~mm}$ in TL; B: Juvenile, $26.09 \mathrm{~mm}$ in TL; C: Subadult, $33.25 \mathrm{~mm}$ in TL; D: Subadult, $34.97 \mathrm{~mm}$ in TL; E: Adult, $47.25 \mathrm{~mm}$ in TL; F: Adult, $53.62 \mathrm{~mm}$ in TL

Table 1. Collection data for Kichulchoia brevifasciata, used to investigate color pattern changes on the head

\begin{tabular}{ccccc}
\hline Collected date & $\begin{array}{c}\text { Examined } \\
\text { specimens }\end{array}$ & $\begin{array}{c}\text { TL } \\
(\mathrm{mm})\end{array}$ & $\begin{array}{c}\text { No. of } \\
\text { dots }\end{array}$ & $\begin{array}{c}\text { Stripe } \\
\text { band }\end{array}$ \\
\cline { 4 - 5 } (On the head) \\
August 26, 2006 & 5 & $10-20$ & $6 \pm 2$ & vivid \\
March 24. 2007 & 7 & $20-30$ & $17 \pm 4$ & vivid \\
September 10.2007 & 9 & $30-40$ & $20 \pm 2$ & faint \\
September 24.2007 & 5 & $40-50$ & $30 \pm 4$ & faint \\
September 24.2007 & 5 & $50-60$ & $33 \pm 3$ & lost \\
\hline
\end{tabular}

\section{Color in spawning season}

The opercle and rim of the opercular region became bright golden-greenish, the hue extending to the base of the pectoral fin (Fig. 4-B) than non-spawning season (Fig. 4-A). Each pectoral fin ray was characterized by a golden glitter. The sex for breeding color could not be verified because $K$. brevifasciata doesn't have distinct external sexual dimorphisms.

\section{Comparison of morphometric data between females and males}

No clear sexual dimorphism in morphometric char- 
acters was apparent between 10 males and 10 females ( $P>0.05$, two tailed Student's $t$-test, $\mathrm{n}=20$ ), although females were larger than males, 41.0 to 49.8 and 33.6 to $43.4 \mathrm{~mm}$ SL, respectively $(P<0.001$, two tailed Student's $t$-test, $\mathrm{n}=20$ ) (Table 2).

\section{DISCUSSION}

Three endemic Korean cobitid genera, Iksookimia, Koreocobitis and Kichulchoia, are separated from
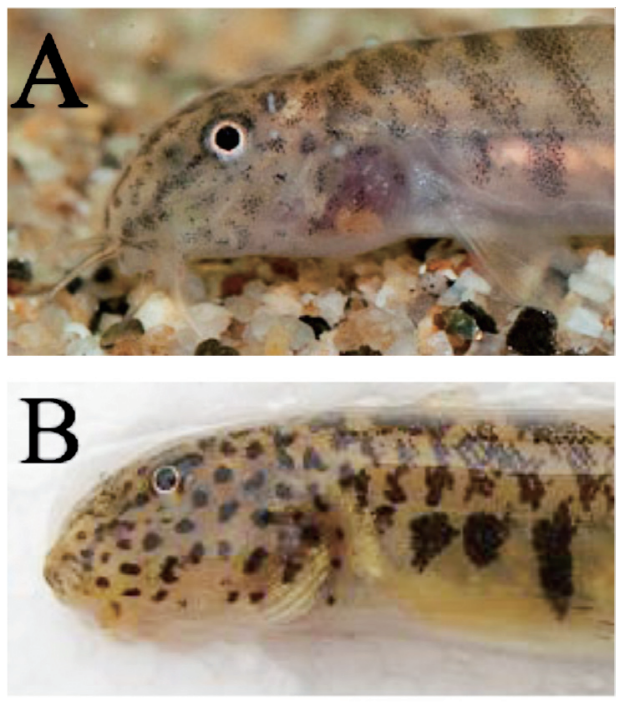

Fig. 4. Kichulchoia brevifasciata colors during non-spawning season (A) and spawning season (B), June, 2006.

A: $54.55 \mathrm{~mm}$ in TL; B: $57.31 \mathrm{~mm}$ in TL
Cobitis on the basis of presence or absence of Gambett's zones on the side of the body, body color pattern, the form of the lamina circularis (in males), numbers of unbranched anal fin rays and molecular data (Nalbant, 1993; Kim et al., 1997; Kim et al., 1999; Kim, 2009). Kim and Lee (1995) noted that K. brevifasciata resembled Iksookimia koreensis and I. longicorpa in appearance, whereas Kim et al. (1997) considered it similar to $I$. koreensis and I. pumila. However, the present study demonstrated notable color pattern differences between $K$. brevifasciata and species in closely-related genera.

Clearly $K$. brevifasciata has a greater range of color variations than previously recognized; dorsal blotches numbering 13 25 (cf. 17 21 in Kim and Lee, 1995) and comprising 3 types of shape variations (Fig. 1) (cf. horizonal bands in I. koreensis in Kim, 1975). Continuous color patterns with irregular speckles (Kim and Lee, 1995) on the upper body were represented by 2 types, including many narrow bands (Fig. 2-A), as in I. pumila (Kim and Lee, 1987) and I. longicorpa (Kim et al., 1976) and wide bands with distinctive cloudy speckles (Fig. 2-B, C and D) as in I. koreensis. In addition, $K$. brevifasciata had a greater range of markings on the side of the body (12-22 cf. 13-19 in Kim and Lee, 1995) with greater variations in form and length, including ventrally-directed extensions (Fig. 2), than in Iksookimia.

Local variations, resulting in differing color patterns, in Niwaella delicate, have been reported (Niwa, 1976) and Kitagawa et al. (2001) noted that although two morphological types of that species could be recognized (allied to distribution patterns), genetic analysis revealed intraspecific level differentiation only. The non-occur-

Table 2. Comparison of morphological proportional measurements** of female and male Kichulchoia brevifasciata from Geumsan-myeon, Goheung-gun, Jeollanam-do, Korea

\begin{tabular}{|c|c|c|c|c|c|c|c|}
\hline & \multicolumn{3}{|c|}{$\begin{array}{c}\text { Females } \\
\text { (10 specimens) }\end{array}$} & \multicolumn{3}{|c|}{$\begin{array}{c}\text { Males } \\
\text { (10 specimens) }\end{array}$} & \multirow{2}{*}{$P^{*}$} \\
\hline & Mean & Range & $\mathrm{SD}$ & Mean & Range & $\mathrm{SD}$ & \\
\hline Standard length (mm) & 46.5 & $41.0-49.8$ & 3.2 & 37.5 & $33.6-43.4$ & 3.1 & $<0.001$ \\
\hline \multicolumn{8}{|l|}{ In standard length (\%) } \\
\hline Head length & 18.3 & $17.0-19.3$ & 0.7 & 19.2 & $17.4-20.9$ & 1.1 & 0.1 \\
\hline Body depth & 12.7 & $10.9-14.0$ & 0.9 & 12.0 & $10.8-12.8$ & 0.7 & 0.1 \\
\hline Predorsal length & 57.9 & $56.5-59.8$ & 1.0 & 57.7 & $56.3-59.0$ & 0.9 & 0.6 \\
\hline Preventral length & 58.2 & $56.6-59.2$ & 0.8 & 57.8 & $56.0-59.4$ & 1.1 & 0.4 \\
\hline Preanal length & 79.3 & $77.9-80.6$ & 0.9 & 78.7 & $77.4-80.9$ & 1.1 & 0.1 \\
\hline Ventral-anal length & 22.9 & $20.5-24.2$ & 1.1 & 22.2 & $20.1-23.9$ & 1.4 & 0.3 \\
\hline Caudal peduncle length & 15.9 & $14.8-17.0$ & 0.6 & 15.9 & $14.2-17.5$ & 1.0 & 0.9 \\
\hline Caudal peduncle depth & 10.6 & $9.7-11.5$ & 0.6 & 11.1 & $10.3-11.7$ & 0.5 & 0.1 \\
\hline \multicolumn{8}{|l|}{ In head length (\%) } \\
\hline Snout length & 44.0 & $41.0-47.0$ & 2.0 & 43.2 & $40.2-45.8$ & 2.1 & 0.5 \\
\hline Eye diameters & 16.2 & $14.4-17.4$ & 0.9 & 15.4 & $13.8-17.3$ & 1.1 & 0.1 \\
\hline Interorbital width & 17.9 & $12.5-20.7$ & 2.4 & 17.3 & $13.9-22.6$ & 2.7 & 0.7 \\
\hline 3rd barbel length & 30.2 & $26.1-34.2$ & 2.4 & 28.3 & $23.2-32.3$ & 3.2 & 0.2 \\
\hline
\end{tabular}

*By two tailed Student's $t$-test

** Following Hubbs and Lagler (2004) 
rence of other cobitid fishes in the present study area and consistency in morphological characters of $K$. brevifasciata suggest that the color pattern variants may be significant only at the intraspecific level or lower.

Color pattern changes on the side of the body have been reported during the spawning season in Korean Cobitis lutheri (Kim, 1997). Although K. brevifasciata showed no spawning-associated color pattern changes on the body, a bright golden-greenish hue was apparent from the opercular region to the rim of the pectoral fin, the rays of the latter having a golden glitter.

Cobitid species show sexual dimorphism as follows: females longer than males (Kim and Ko, 2005), pectoral fin with a lamina circularis and a sharp margin in males (except in Niwaella and Kichulchoia) (Kim, 1997; Kim, 2009). Although Cobitis shikokuensis also lacks a lamina circularis, some pectoral fin branched rays are thickened with sharp margins in males (Suzawa, 2006). The present investigation of $K$. brevifasciata found females to be 5 to $20 \mathrm{~mm}$ larger than males, but no other sexually dimorphic characters were apparent.

Cobitis and Iksookimia species generally have a distinct line on the head running obliquely from the tip of the snout to the edge of the eye (Kim, 1997; Kim, 2009) and Suzawa (2006) used existence of a similar band on the cheek to distinguish between $C$. takatsuensis and $C$. shikokuensis. Although $K$. brevifasciata and the genus Niwaella have been reported as not having a line from the snout tip to the eye (Kim and Lee, 1995; Kim, 1997; Kim, 2009), such a line was apparent in immature specimens examined during the present study, gradually disappearing with growth. Because developmental characters are the proximate cause of morphological traits acquired during evolution (Laubichler, 2000), seen in modifications of the second pectoral fin ray present in ancestral Cobitidae and lost in Niwaella, Kichulchoia and Sabanejewia (Šlechtová et al., 2008), an oblique line on the head may also be considered to be an ancestral developmental character of Cobitidae.

\section{ACKNOWLEDGEMENTS}

This study was warmly supported by Dr. Ik-Soo Kim (Chonbuk National University, Korea). We are very grateful to Dr. Kazumi Hosoya (Kinki University, Japan) for his thoughtful encouragement and valuable comments, and also to Dr. G. S. Hardy (Ngunguru, New Zealand) for his English correction and advice for improving the manuscript. We also thank to Dr. Kosuke Takaku (Japan wildlife research center) for providing a photo used in the present study. The final manuscript was prepared with the support of the Ministry of Education, Culture, Sports, Science \& Technology (MEXT), Japan.

\section{REFERENCES}

Chae, B. S. and H. N. Yoon 2007 Freshwater fish fauna of the Yeosu peninsula and Geumo Islands, Korea (in Korean with English summary). Korean J. Ichthyol., 19: 225-235

Gambetta, L. 1934 Sulla variabilita del cobite fluviale (Cobitis tae- nia L.) e sul rapporto numerico dei sessi. Boll. Mus. Zool. Anat. Comp. R. Univ. Torino, 44: 297-324

Hubbs, C. L. and K. F. Lagler 2004 Fishes of the Great Lakes region (Revised by G.R. Smith). The University of Michigan Press, Ann Arbor, pp. 31-39

Kim, I. S. 1975 A new species of cobitid fish from Korea (Cobitis koreensis). Korean J. Lim., 8: 51-57

Kim, I. S., K. C. Choi and T. Nalbant 1976 Cobitis longicorpus, a new cobitid fish from Korea. Korean J. Zool., 19: 171-178

Kim, I. S. and W. O. Lee 1987 A new subspecies of cobitid fish (Pisces: Cobitidae) from the Paikchon stream, Chollabuk-do, Korea. Korean J. Syst. Zool., 3: 57-62

Kim, I. S. and W. O. Lee 1995 Niwaella brevifasciata, a new cobitid fish (Cypriniformes: Cobitidae) with a revised key to the species of Niwaella. Ichthyol. Res., 42: 285-290

Kim, I. S. 1997 Illustrated encyclopedia of fauna \& flora of Korea (in Korean). Vol 37 Freshwater Fishes. Ministry of Education (Seoul), p. 629

Kim, I. S., J. Y. Park and T. T. Nalbant 1997 Two new genera of loaches (Pisces: Cobitidae: Cobitinae) from Korea. Trav. Mus. Nus. Natl. Hist. Nat (Grigore Antipa), 39: 191-195

Kim, I. S., J. Y. Park and T. T. Nalbant. 1999 The far-east of the Genus Cobitis with the description of three new taxa (Pisces: Ostariophysi: Cobitidae). Trav. Mus. Nus. Natl. Hist. Nat. (Grigore Antipa), 41: 373-391

Kim, S. Y., I. S. Kim, K. Y. Jahng and M. H. Chang 2000 Molecular phylogeny of Korean loaches inferred from mitochondrial DNA cytochrome $b$ sequence. Korean J. Ichthyol., 12(4): 223-229

Kim, I. S. and M. H. Ko 2005 Ecology of Iksookimia longicorpa (Cobitidae) in the Seomjin River, Korea (in Korean with English summary). Korean J. Ichthyol., 17(2): 112-122

Kim, I. S. and E. J. Kim 2008 Karyotype of dwarf loach, Kichulchoia brevifasciata (Pisces: Cobitidae) from Korea. Korean J. Ichthyol., 20: 61-65

Kim, I. S. 2009 A review of the spined loaches, family Cobitidae (Cypriniformes) in Korea. Korean J. Ichthyol., 21(Suppl.) $7-28$

Kitagawa, T., M. Yoshioka, M. Kashiwagi and T. Okazaki 2001 Population structure and local differentiation in the delicate loach, Niwaella multifasciata, as revealed by mitochondrial DNA and morphological analyses. Ichthyol. Res., 48: 127-135

Laubichler, M. D. 2000. Homology in development and the development of the homology concept. Amer. Zool., 40: 777-788

Mizuno, N. 1970 A new species of cobitid fish from Japan (Cobitis takatsuensis). Mem. Ehime Univ. Sci. ser. B (Biol.), 6(3): 133-143

Nalbant, T. T. 1963 A study of the genera of Botinae and Cobitinae (Pices, Ostariophysi, Cobitidae). Trav. Mus. Hist. Nat. (Grigore Antipa), 4: 343-379

Nalbant, T. T. 1993 Some problems in the systematics of the genus Cobitis and its relatives (Pisces, Ostariophysi, Cobitidae). Rev. Roum. Biol. (Biol. Anim.), 38: 101-110

Nelson, J. S. 2006 Fishes of the World. Fourth ed. John Wiley and Sons. New York, p. 601

Niwa, H. 1976 Adime. Comprehensive studies on Niwaella delicata (Niwa), a Japanese species of Cobitidae (in Japanese). Taishu-Shobou, Gifu, Japan

Saitoh, K. and H. Aizawa 1987 Local differentation whitin the striated spined loach (the striata type of Cobitis taenia complex). Japanese J. Ichthyol., 34(3): 334-345

Šlechtová, V., J. Bohlen and A. Perdices 2008 Molecular phylogeny of the freshwater fish family Cobitidae (Cypriniformes: Teleostei): Delimination of genera, mitochondrial introgression and evolution of sexual dimorphism. Mol. Phylogenet. Evol., 47: $812-831$

Suzawa, Y. 2006 A new loach, Cobitis shikokuensis (Teleostei: Cobitidae), from Shikoku Island, Japan. Ichthyol. Res., 53 315-322

Vladykov, V. D. 1935 Secondary sexual dimorphism in some Chinese cobitid fishes. J. Morph., 57: 275-302 